\title{
An Evolutionary Algorithm Approach to Modelling of Tsunami Wave Force
}

\author{
Meyyappan $\mathrm{PL}^{1,{ }^{*}}$, Sivapragasam $\mathrm{C}^{1}$, and Sekar $\mathrm{T}^{2}$ \\ ${ }^{1}$ Centre for Water Technology, Civil Department, Kalasalingam Academy of Research and Education, Krishnankoil 626126, India \\ ${ }^{2}$ Civil Department, University College of Engineering, Ramanathapuram 623513, India
}

\begin{abstract}
Estimation of design load for tsunami resistant structures is important. Though standard codes such as FEMA exist and are widely used, this study recommends that it is preferable to conduct model studies as per the need to estimate the expected force. The distribution of force can significantly change based on the type and shape of the structure as well any other internal or external arrangements made for its protection. In this study, the specific case of a building without stilt column and provided with barriers as external protection measures is considered. It is demonstrated that Genetic Programming (GP) is a potential modelling technique to model the data/information obtained from force sensors fitted at different levels. For each type of dwelling units, similar independent model studies are recommended to be carried out.
\end{abstract}

\section{Introduction}

It is understood that most of the researchers have used FEMA based equations for estimating hydrodynamic forces which is reported to overestimate the experimental values because of certain assumptions such as flow velocity calculated based on Peregrine and Williams's formulae of dimensionless flow velocity, hydro static distribution for the wave run up equal to two times the wave height, steady state flow condition, irregularities in wave force nature, uniform flow, absence of barriers etc (Harada [2002], Harry yeh [2007], Madurapperuma [2008], Fujima [2009], Palermo [2009], Srivastava [2009]). The FEMA recommends that the tsunami loads to be considered in combination with gravity and live loads while designing a building. It is identified that the values for drag coefficient is taken in the range of 1.0 to 3.0 for the shapes of cubical, circular, rectangular structures (Madurapperuma [2008], Palermo [2009], Rao [2010], Suppasri [2010]). The hydrodynamic and impact forces from tsunami water-borne massive objects are normally more predominant in nature in the analysis of tsunami coastal structures subjected to tsunami wave forces. Moreover, the hydrodynamic force can also cause localized damage to structural elements, including out-of- plane failure of walls and scour/foundation failure, which could lead to progressive collapse of the building (Christopher koutitas [2005], Pimanmas, [2010], Kircher [2014]). Hence hydrodynamic forces should be estimated accurately as far as possible. This study suggests that hydrodynamic forces should be estimated based on model studies which will differ depending on the type of structure being modeled. Further, the study also suggests to provide barriers as protection measures with a detailed analysis of its effect in reducing the hydrodynamic force.

\section{Experimental setup}

Creation of tsunami wave is the most important of all the factors before any tsunami related work can be carried out. The wave nature has to closely match the expected tsunami. Since there is no common agreement amongst the researchers in the procedure adopted for creating tsunami waves in the laboratory. In order to estimate the impact forces, experiments can be preferred in a small level wave flume tank with simple wave creating mechanisms. The wave flume tank of size $10 \mathrm{~m}$ x $1.5 \mathrm{~m}$ x $1 \mathrm{~m}$ is kept for this study. In the present study, series of waves were created by using paddle type mechanism which is operated manually at a constant rate of 60 strokes per minute for generating low level tsunami waves as shown in Figure 1. Building models without stilt column were fabricated at a scale ratio of 1:25 for a prototype $7 \mathrm{~m}$ in length, $4 \mathrm{~m}$ in width and $6 \mathrm{~m}$ in height including the central rise of $2 \mathrm{~m}$ as shown in Figure 2 . This is in line with the requirements of Indian National Building Code (NBC) which requires a minimum plinth area of $14.5 \mathrm{~m} 2$ for occupancy of 4 members of the family. No provisions for partitions are made in the model. The pictorial view of the building model is shown in Figure 2. The fabricated model structure is placed in the tsunami wave flume tank for testing its impact wave force. The building orientation is kept as width perpendicular to the waves created in the flume tank. The openings in the model are closed during testing (as followed by previous researches John W. Van

\footnotetext{
* Corresponding author: meyyappan $@$,klu.ac.in
} 
de Lindt [37], Jebediah S. Wilson [36]) in order to examine the critical condition. The placement of force sensors at floor level and roof level of the model structure. For this experimental study, the waves are created in the range of 0.1 $\mathrm{cm}$ to $7 \mathrm{~cm}$ heights and the model is tested in the absence of barriers. The experiment is repeated for 50 trials. Among these trials, 5 samples of the maximum impact force recorded are grouped for the wave height range of $0.1-1.0 \mathrm{~cm}, 1.1$ $2.0 \mathrm{~cm}, 2.1-3.0 \mathrm{~cm}, 3.1-4.0 \mathrm{~cm}, 4.1-5.0 \mathrm{~cm}, 5.1-6.0 \mathrm{~cm}$ and $6.1-7.0 \mathrm{~cm}$. Barriers are introduced to see how it reduces the impact force which is acting on the model structure. The idea of providing natural / artificial reef barriers have been discussed in the previous works as there is considerable amount of reduction in energy (Eddie Bernard [14], Kenji harada [15], Bleck [16]). A set of five barriers with zig-zag arrangement of height and diameter are kept as $7.5 \mathrm{~m}$ and $3.75 \mathrm{~m}$ respectively in a prototype scale of 1:25 (to resemble the actual height of mangroves) are introduced in the wave flume tank at the shore just $2 \mathrm{~m}$ ahead of the building model. All the barriers are kept equal spaced. The proposed work doesn't measure velocity and frequency of the wave (which some of the previous researchers have measured to estimate force); rather force is directly estimated through force sensor. The scope of the paper is restricted to estimate the force in presence of barriers.

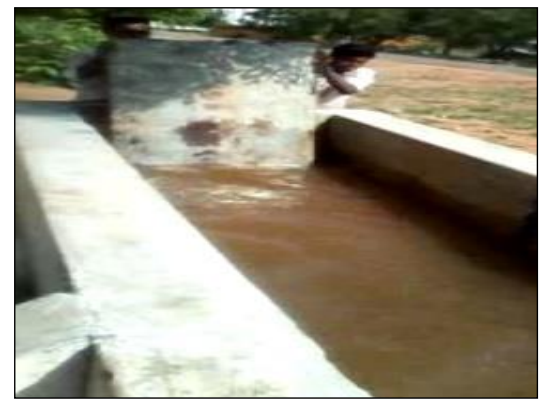

Fig. 1. Waves created by using paddle mechanism

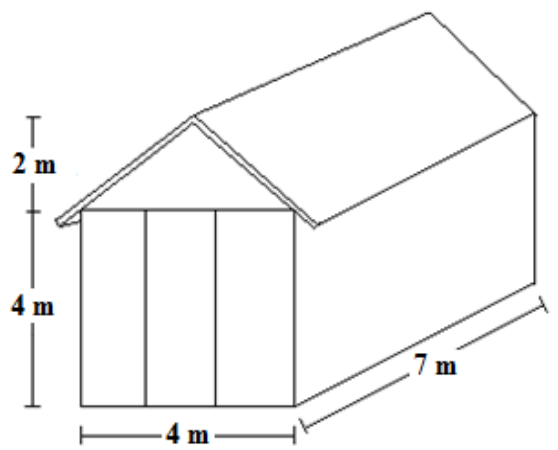

Fig. 2. Schematic diagram of a building model

\section{Results and discussions}

Tables 1 and 2 show the experimental results of model without and with barrier arrangements.

\subsection{Without barriers}

In the absence of barriers, the waves created in the wave flume tank strike with full impact on the model structure without stilt column. Since in the absence of barriers, the model structure is subjected to a large impact force (hydro dynamic force). From Table 1, it is understood that as wave height increases impact force also increases. The average impact force and maximum impact force recorded in the model in the absence of barriers is $199 \mathrm{~N}$ and $208 \mathrm{~N}$ in floor level whereas in roof level it is $149 \mathrm{~N}$ and $157 \mathrm{~N}$ respectively for the wave height $7 \mathrm{~cm}$. In Figure 3, the graph represents non-linear trend. For wave height $6 \mathrm{~cm}$ to $7 \mathrm{~cm}$, there is a sudden rise in the impact force in both floor and roof levels. For the waves of height $1 \mathrm{~cm}$ to $5 \mathrm{~cm}$, average impact force in the roof level is in the range of $70 \%-100 \%$ of average impact force in the floor level whereas for waves of height above $5 \mathrm{~cm}$ average impact force in the roof level is only around $30 \%$ of average impact force in the floor level. In design both floor and roof levels should be designed for the maximum capacity of impact force. 


\subsection{With barriers}

A set of five barriers in zig-zag arrangement is placed infront of the model for the waves to strike the barriers instead arrangement is placed in front of the model for the waves to strike the barriers instead of striking the model directly.

Table 1. Impact forces on model without barrier arrangements

\begin{tabular}{|c|c|c|c|c|c|c|c|c|}
\hline \multirow{2}{*}{$\begin{array}{c}\text { Description } \\
\text { of wave } \\
\text { height in } \\
\text { cm }\end{array}$} & \multirow{2}{*}{$\begin{array}{c}\text { Location } \\
\text { of } \\
\text { Sensor }\end{array}$} & \multicolumn{5}{|c|}{ Force induced on building model in $\mathrm{N}$} & \multirow{2}{*}{$\begin{array}{c}\text { Avg. } \\
\text { Force } \\
\text { induced } \\
\text { in the } \\
\text { model } \\
\text { in N } \\
\end{array}$} & \multirow{2}{*}{$\begin{array}{c}\text { Max. } \\
\text { Force } \\
\text { induced } \\
\text { in the } \\
\text { model in } \\
\mathbf{N}\end{array}$} \\
\hline & & $\begin{array}{c}\text { Trial } \\
\text { I }\end{array}$ & $\begin{array}{c}\text { Trial } \\
\text { II }\end{array}$ & $\begin{array}{c}\text { Trial } \\
\text { III }\end{array}$ & $\begin{array}{c}\text { Trial } \\
\text { IV }\end{array}$ & $\begin{array}{c}\text { Trial } \\
\text { V }\end{array}$ & & \\
\hline \multirow{2}{*}{1} & Floor & 7 & 11 & 6 & 7 & 9 & 8 & 11 \\
\hline & Roof & 4 & 6 & 3 & 4 & 5 & 4 & 6 \\
\hline \multirow{2}{*}{2} & Floor & 18 & 23 & 26 & 15 & 22 & 21 & 26 \\
\hline & Roof & 9 & 12 & 14 & 8 & 11 & 11 & 14 \\
\hline \multirow{2}{*}{3} & Floor & 40 & 38 & 46 & 51 & 35 & 42 & 51 \\
\hline & Roof & 21 & 20 & 24 & 27 & 18 & 22 & 27 \\
\hline \multirow{2}{*}{4} & Floor & 64 & 69 & 76 & 70 & 59 & 68 & 76 \\
\hline & Roof & 38 & 41 & 45 & 35 & 41 & 40 & 45 \\
\hline \multirow{2}{*}{5} & Floor & 89 & 95 & 103 & 113 & 98 & 100 & 113 \\
\hline & Roof & 53 & 56 & 61 & 67 & 58 & 59 & 67 \\
\hline \multirow{2}{*}{6} & Floor & 111 & 115 & 123 & 117 & 121 & 117 & 123 \\
\hline & Roof & 86 & 89 & 84 & 93 & 87 & 88 & 93 \\
\hline \multirow{2}{*}{7} & Floor & 188 & 195 & 208 & 197 & 205 & 199 & 208 \\
\hline & Roof & 146 & 151 & 142 & 157 & 149 & 149 & 157 \\
\hline
\end{tabular}

Table 2. Impact forces on model with barrier arrangements

\begin{tabular}{|c|c|c|c|c|c|c|c|c|}
\hline \multirow{2}{*}{$\begin{array}{c}\text { Description } \\
\text { of wave } \\
\text { height in } \\
\text { cm }\end{array}$} & \multirow{2}{*}{$\begin{array}{c}\text { Location } \\
\text { of } \\
\text { Sensor }\end{array}$} & \multicolumn{5}{|c|}{ Force induced on building model in $\mathrm{N}$} & \multirow{2}{*}{$\begin{array}{c}\text { Avg. } \\
\text { Force } \\
\text { induced } \\
\text { in the } \\
\text { model } \\
\text { in } N \\
\end{array}$} & \multirow{2}{*}{$\begin{array}{c}\text { Max. } \\
\text { Force } \\
\text { induced } \\
\text { in the } \\
\text { model in } \\
\mathbf{N} \\
\end{array}$} \\
\hline & & $\begin{array}{c}\text { Trial } \\
\text { I }\end{array}$ & $\begin{array}{c}\text { Trial } \\
\text { II }\end{array}$ & $\begin{array}{c}\text { Trial } \\
\text { III }\end{array}$ & $\begin{array}{c}\text { Trial } \\
\text { IV }\end{array}$ & $\begin{array}{c}\text { Trial } \\
\mathbf{V}\end{array}$ & & \\
\hline \multirow{2}{*}{1} & Floor & 2 & 3 & 2 & 2 & 3 & 2 & 3 \\
\hline & Roof & 1 & 2 & 1 & 1 & 2 & 1 & 2 \\
\hline \multirow{2}{*}{2} & Floor & 6 & 8 & 9 & 5 & 7 & 7 & 9 \\
\hline & Roof & 3 & 4 & 5 & 3 & 4 & 4 & 5 \\
\hline \multirow{2}{*}{3} & Floor & 14 & 13 & 16 & 17 & 12 & 14 & 17 \\
\hline & Roof & 7 & 7 & 8 & 9 & 6 & 7 & 9 \\
\hline \multirow{2}{*}{4} & Floor & 22 & 23 & 25 & 24 & 20 & 23 & 26 \\
\hline & Roof & 12 & 14 & 15 & 13 & 12 & 13 & 15 \\
\hline \multirow{2}{*}{5} & Floor & 30 & 32 & 35 & 38 & 33 & 34 & 38 \\
\hline & Roof & 18 & 19 & 21 & 23 & 20 & 20 & 23 \\
\hline \multirow{2}{*}{6} & Floor & 49 & 51 & 48 & 53 & 51 & 50 & 53 \\
\hline & Roof & 29 & 30 & 29 & 32 & 30 & 30 & 32 \\
\hline \multirow{2}{*}{7} & Floor & 64 & 66 & 71 & 67 & 70 & 68 & 71 \\
\hline & Roof & 38 & 42 & 39 & 41 & 40 & 40 & 42 \\
\hline
\end{tabular}


When the waves striking the zigzag arrangement of barriers, the energy level of impact waves is reduced because of its arrangements at two levels. The maximum impact forces recorded in the floor level with the provisions of zig-zag arrangement are $71 \mathrm{~N}$ for the set of five barriers (Table 2). In the roof level, $42 \mathrm{~N}$ are recorded for the set of five numbers of barriers respectively. The percentage of force reduction is around $66 \%$ and $73 \%$ for a set of five barriers when compared with no barriers for the maximum wave height $7 \mathrm{~cm}$.

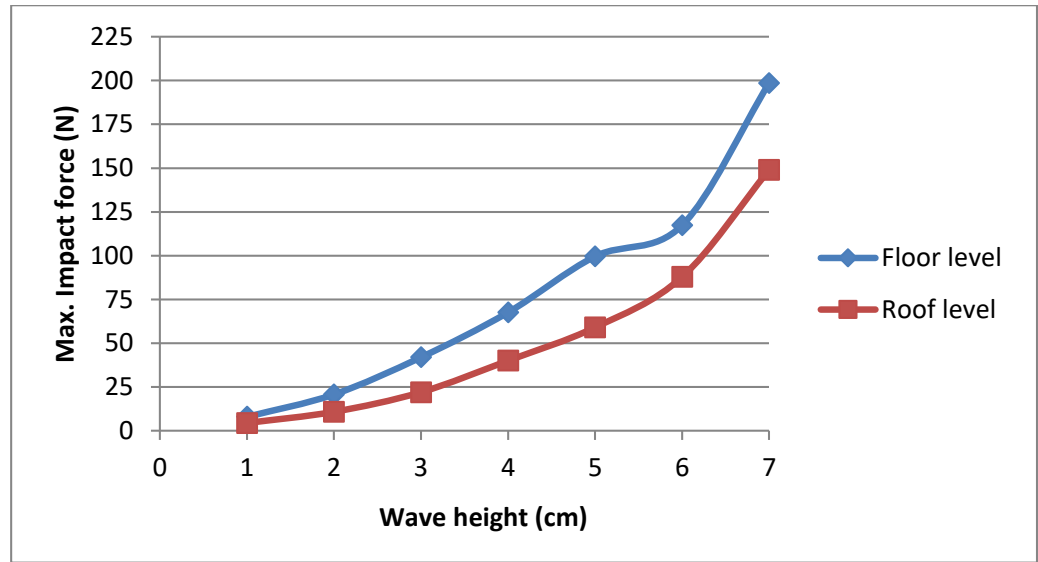

Fig. 3. Maximum impact force Vs wave height for model without barriers

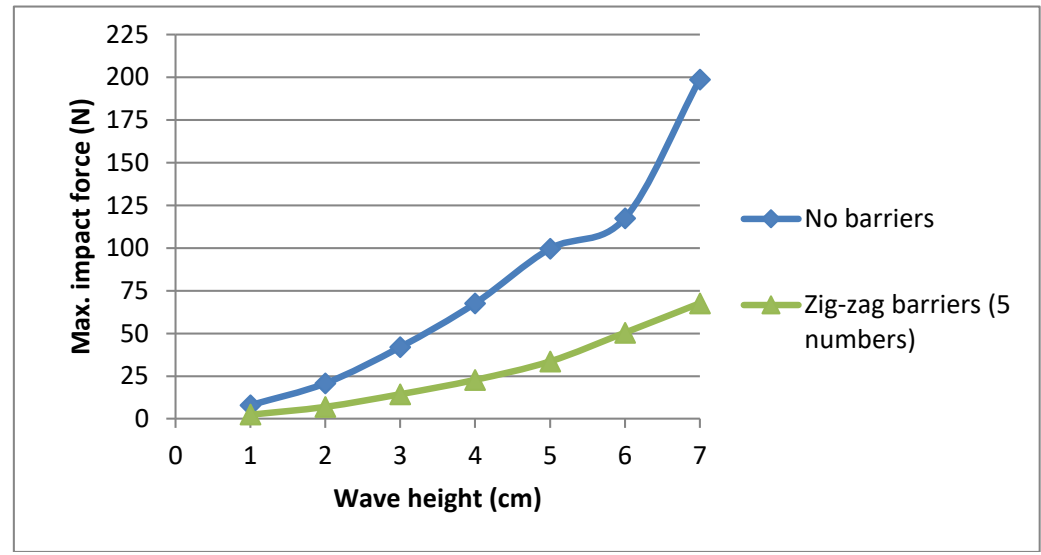

Fig. 4. Comparison of maximum impact force on floor level of model with and without barriers

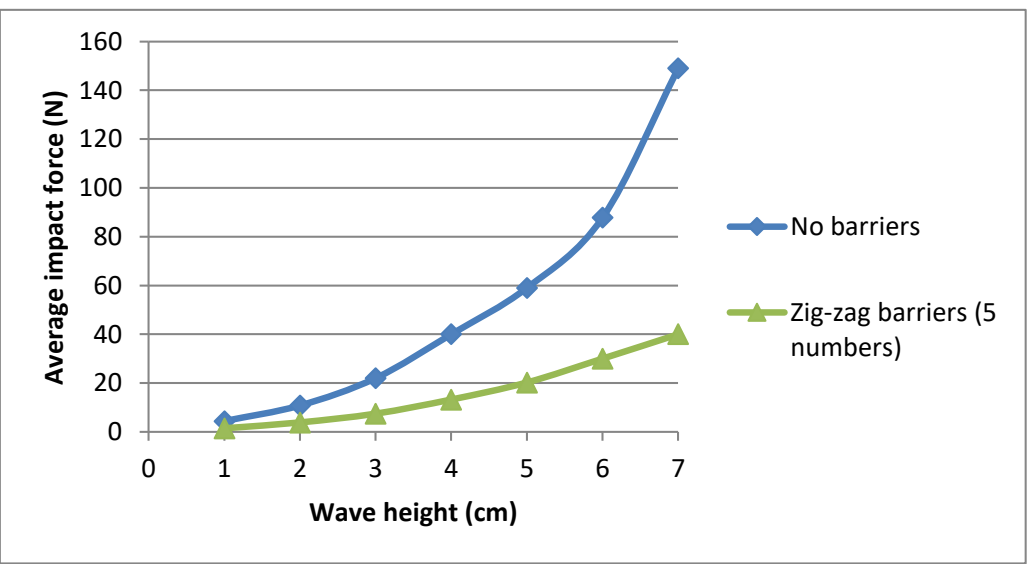

Fig. 5. Comparison of maximum impact force on roof level of model with and without barriers 
Figure 4, shows a nonlinear effect and it is understood that, the force reduction is uniform around $25 \%$ for all range of wave heights in both floor and roof levels on the model in the presence of five sets of zig-zag barrier arrangements. Moreover, the force reduction is around $66 \%$ for a set of five barriers in the floor levels for a wave height of $1 \mathrm{~cm}$ to 7 $\mathrm{cm}$ when compared with the absence of barriers. In roof levels (Figure 5), for wave height $7 \mathrm{~cm}$ the force reduction is $73 \%$ for a set of five barriers, whereas for other wave heights the force reduction is $65 \%$.

Table 3. Comparison of Reduction of Impact forces

\begin{tabular}{|c|c|c|}
\hline $\begin{array}{c}\text { Wave } \\
\text { height, in } \\
\text { cm }\end{array}$ & $\begin{array}{c}\text { Location of } \\
\text { the model }\end{array}$ & $\begin{array}{c}\text { Percentage of max. impact } \\
\text { force reduction compared with } \\
\text { model without barrier }\end{array}$ \\
\hline \multirow{2}{*}{1} & Floor level & 37 \\
\cline { 2 - 3 } & Roof level & 25 \\
\hline \multirow{2}{*}{2} & Floor level & 43 \\
\cline { 2 - 3 } & Roof level & 45 \\
\hline \multirow{2}{*}{3} & Floor level & 41 \\
\cline { 2 - 3 } & Roof level & 41 \\
\hline \multirow{2}{*}{4} & Floor level & 40 \\
\cline { 2 - 3 } & Roof level & 40 \\
\hline \multirow{2}{*}{5} & Floor level & 39 \\
\cline { 2 - 3 } & Roof level & 39 \\
\hline \multirow{2}{*}{6} & Floor level & 22 \\
\cline { 2 - 3 } & Roof level & 40 \\
\hline \multirow{2}{*}{7} & Floor level & 40 \\
\cline { 2 - 3 } & Roof level & 52 \\
\hline
\end{tabular}

From Table 3 shows the comparison of reduction of max. impact force for model structure with barrier arrangements compared with no barrier arrangements. It is understood that, for wave height of $7 \mathrm{~cm}$, the barriers conditions are effective than compared with other wave heights. From the overall, it seems that, the maximum force reduction is on the set of 5 barriers in zig-zag arrangement) of around $75 \%$ than compared to without barriers conditions. The peak rise of the average impact force is observed in the wave height $7 \mathrm{~cm}$ for the without barriers conditions and this can be effectively controlled by the presence of barriers of different arrangement. It seems that the arrangement of zig-zag barriers performs better in reducing the impact force than series barriers, since the arrangement is like two-layer arrangement. When the wave strikes the first layer, its energy gets dissipated and then when it again strikes the second layer, there is further dissipation of energy. Hence as the waves reach the model, the amplitude and energy levels are greatly reduced. Even this is better, when the numbers of barrier is increased in this arrangement. The hydrodynamic force and uplift force on the model is drastically reduced by the presence of zig-zag arrangement of barriers. Though the reduction in force impact may be more with increase in number of barriers, the exact numbers need to be decided on a case-to-case basis to arrive at economical design. The hydrodynamic force and uplift force on the model is reduced by the presence of series arrangement of barriers.

\section{Modeling of Impact force}

Genetic Programming (GP) is a technique which enables computers to solve problems without being explicitly programmed. It is a subset of genetic algorithms. The members of the population are the parse trees of computer programs whose fitness is evaluated by running them. This is achieved by acting upon sub trees. The parameters involved in this genetic programming is Crossover rate, mutation rate, population size, instruction set, distribution of initial program sizes, termination criteria, and parsimony pressure (fitness advantages for smaller programs). Training and validation sets are simple delimited ASCII files, with inputs and output in columns, and so are easy to create.The supplied fitness functions for function fitting are the usual ones: difference between target and evolved output, squared or averaged. Recently GP has been extensively used to resolve various industrial problems in modeling, process monitoring and optimization and new product development.

GP has been used for mathematical modelling of the impact waves striking at the structure. A total of $50 \%, 35 \%$ and $15 \%$ data (Table 1 and 2) have been taken for training, testing and validation respectively. Apart from the arithmetic functions, it is preferred to keep the trigonometric functions as well due to the fact that usually the waves are a complex combination of sine or cosine waves. Equation 1 and 2 gives the forces without barrier arrangement on floor and roof respectively.

$$
\begin{aligned}
& F=\operatorname{Sin}^{2}[1.55 \operatorname{Cos} h-3 h-3.16]+4 h^{2} \\
& \left.F=2 h\left[\operatorname{Sin}^{2} h-\operatorname{Sin} h\right]+3 h^{2}-2 h\right]
\end{aligned}
$$

Where, ' $F$ ' is the Impact force of wave striking on the structure and ' $h$ ' is the height of the wave. 
In the presence of the barriers, the force experienced at floor and roof level are given by equation 3 and 4 respectively.

$$
\begin{gathered}
F=1.268 h^{2}-0.77 h \\
F=0.804 h^{2}+0.106 h
\end{gathered}
$$

A closer look at the equations reveals the following:

a) The force equation for without barrier condition indicates that the sinusoidal nature of wave is preserved while striking the structure (as reflected by the 'sine' function). However, in the presence of barriers, this nature of the wave doesn't exist. The wave nature affects the degree of impact on the structure.

b) With increase in the height of waves, the force experienced increases. However in the presence of barriers, the magnitude of such increase is much lesser when compared to without barrier. This is reflected from the values of coefficients associated with ' $h$ ' in equation 3 and 4.

c) Comparing the force experienced at floor and roof level, the force at both levels have almost similar form indicating similar effect.

\section{Conclusion}

(i) A set of five barriers in zig-zag arrangement seems to be effective with $75 \%$ force reduction, when compared with model without barrier.

(ii) In model equation, it is understood that the sinusoidal effect of the wave nature is reduced to quadratic form by the presence of barriers.

(iii) From the experimental work, it is understood that providing barrier height as half the height of structure can be sufficient to reduce the impact energy. Since the nature of tsunami and its damages are quite different when compared to other disasters, it is worthwhile to provide such barrier arrangements for safety of crucial structures.

\section{References}

1. M. Saatcioglu., A. Ghobarah, I. Nistor, ISET Journal of Earthquake Technology, 42, 79 (2005)

2. BIS CED 39, Draft Indian Standard Tsunami Resistant Design of Buildings and Structures-Recommendations (2009)

3. N.I. Thusyanthan, A. Modoni, R. Hakin, S.P.G. Madabhushi (2007), Proceedings of ICE Civil Engg 1, 1 (2007)

4. E. Bernard, F. Gonzalex, R. Hagemeyer, National Tsunami Hazard Mitigation Program 1 (2001)

5. Pimanmas, P. Joyklad, P. Warnitchai, Journal of Earthquake and Tsunami, 4, 269 (2010)

6. H. Yeh, Journal of Disaster Research 2, 531 (2007)

7. Nistor, D. Palermo, T. Al-faesly, Proceedings of 33rd IAHR Congress: Water Engineering. Sustainable Environment. 6766 (2008)

8. K.M. Madurapperuma and A. C. Wijeyewickrema, The 14th World Conference on Eq. Engineering 1 (2008)

9. J. A. Heintz, M. Mahoney, Guidelines for Design of Structures for Vertical Evacuation from Tsunami's (2008)

10. S.R.K. Reddy, K. Rama Mohana Rao, International Journal Engineering. Science Technology. 2, 6195 (2010)

11. Srivastava, G.L. Sivakumar Babu, Science of Tsunami Hazards 28, 186 (2009)

12. Koutitas, T. Karambas, ISET Journal of Earthquake Technology 42, 137 (2005)

13. C.A. Kircher, J. Bouabid, New Building Damage and Loss Functions for Tsunami, 21 (2014)

14. E. Bernard, F. Gonzalex, R. Hagemeyer, Seven Principles for Planning and Designing for Tsunami Hazards (2001)

15. K. Harada, F. Imamura, T. Hiraishi, Pro. 12th Int. Offshore and Polar Engg Conference, 652 (2002)

16. M. Bleck, H. Oumeraci, Proceedings of 4th International Conference on Coastal Engineering 2, 1778 (2002)

17. A.S. Arya, Prevention/Protection and Mitigation from Risk of Tsunami Disasters - A Concept Note (2005)

18. V. M. Patel, A.P. Singh, Comparative Study of Earthquake and Tsunami Loading on Vertical Evacuation Structure at Dwarka, International Journal of Earth Sciences and Engineering 4, 659 (2011)

19. Suppasri, S. Koshimura, F. Imamura, Journal of Earthquake and Tsunami 1, 1 (2010)

20. H.R. Riggs, N. Ian Robertson, K. Fai Cheung, Genopawlak, Journal of Disaster Research. 4, 410 (2009)

21. K. Kosa S. Nii, M. Shoji, K. Kimuna, Experimental Study on Tsunami. Waves acting on Bridges, Journal of Structural Engineering, 55A (1). (2009) 